\title{
OS CUIDADOS NO FIM DA VIDA EM PERSPECTIVA BIOÉTICA: UM OLHAR A PARTIR DA FÉ CRISTÃ
}

\author{
Care at the END of LifE In BIOETHICAL PERSPECTIVE: \\ A VIEW FROM THE CHRISTIAN FAITH
}

\author{
Larissa Fernandes Menegatti* \\ Mário Antônio Sanches**
}

\section{RESUMO}

Este artigo propõe refletir o tema sobre cuidados no fim da vida numa perspectiva bioética a partir da fé cristã. Esta contribuição teórica é corroborada pela experiência vivencial de João Paulo II, por meio de seu próprio testemunho nos últimos dias antes de sua morte. De fato, a morte provoca questionamentos profundos com relação à nossa existência marcada pela condição inegável de finitude. Essa realidade fatal é muitas vezes experimentada antes por um ambiente de dor e sofrimento de todas as ordens que nos aflige em nossas enfermidades, pois anuncia com sua chegada a proximidade de nossa partida deste mundo. E por mais que formemos profissionais de saúde focados em conteúdos com ênfase em conhecimentos biotecnológicos, se faz necessária a inserção nos conhecimentos integrados que englobem os referenciais bioéticos a fim de distinguir os processos terapêuticos realizados. Nesse paradigma, a bioética apresenta-se como critério ético nas escolhas relacionadas entre biotecnologia e saúde.

Palavras-chave: Bioética. Morte. Eutanásia. Excesso terapêutico. Ortotanásia.

* Mestre em Teologia pela PUCPR. Membro do Grupo de Pesquisa em Teologia e Bioética. Membro sócia da Sociedade de Teologia e Ciências da Religião - SOTER. Membro Sócia da Sociedade Brasileira de Teologia Moral - SBTM. Missionária na Comunidade Católica Arca da Aliança desde 1998. Presta assessoria e consultoria pastoral nas áreas de Teologia e Espiritualidade. Pastoralista na Faculdade Padre João Bagozzi em Curitiba-PR.

** Mário Antônio Sanches tem pós-doutorado em Bioética pela Pontifícia Universidad Comillas em Madri, professor titular da Pontifícia Universidade Católica do Paraná, em Curitiba, coordenador do Programa de Pós Graduação em Bioética, e professor visitante no Instituto Superior de Filosofia e Teologia D. Jaime Garcia Goulart, Dili, Timor Leste. $<$ m.sanches@pucpr.br>.

\begin{tabular}{|l|l|l|l|l|l|}
\hline Teocomunicação & Porto Alegre & v. 46 & n. 1 & p. $39-58$ & jan.-jun. 2016 \\
\hline
\end{tabular}




\begin{abstract}
This article proposes to reflect the theme of care at the end of life in bioethics from the perspective of the Christian faith. This theoretical contribution is supported by the living experience of John Paul II, through his own testimony in the last days before his death. In fact, death causes profound questions regarding our existence marked by undeniable condition of finitude. This fatal reality is often experienced before for pain and suffering environment of all orders that afflicts us in our infirmities, as announces his arrival in proximity of our departure from this world. And as we build health professionals focused on content with an emphasis on biotechnological knowledge, it is necessary to insert the integrated knowledge covering the bioethical references to distinguish the therapeutic processes performed. In this paradigm, bioethics presents itself as ethical criteria in related choices between biotechnology and health.
\end{abstract}

Keywords: Bioethics. Death. Euthanasia. Therapeutics excess. Orthothanasia.

\title{
Introdução
}

O pensamento do papa João Paulo II (1920-2005) foi marcante para a bioética. Ele acolheu esta área do conhecimento e se posicionou claramente frente às várias questões a ela relacionada: pesquisa biomédica, manipulação de embriões, reprodução medicamente assistida, etc. Entretanto, destacamos aqui o seu posicionamento relacionado aos temas que envolvem o fim da vida humana, pois além da sua relevante contribuição teórica, João Paulo II soube dar um testemunho de coerência com seu ensinamento no próprio modo como viveu seus últimos dias.

O fim da vida coloca-nos muitas questões, principalmente porque diz respeito ao modo como nos compreendemos e ao sentido último de nossa existência. A morte nos leva ao confronto com nossa condição de finitude e, se negamos essa condição, logo recusamo-nos também a pensar na morte. Ela coloca para nós a questão do sentido da vida, se o sentido da vida não está bem definido e vivo em nós, consequentemente preferimos não abordar o tema da morte. Raramente a morte anda só, seus companheiros mais constantes são a dor e o sofrimento, que marcam sua presença por meio de curtas ou longas enfermidades.

Usualmente compreende-se o sofrimento como uma experiência subjetiva, enquanto a dor é vista como uma sensação mais fisiológica, mais objetiva. Sem dúvida, os sofrimentos são de muitos tipos, nem 
todos acompanhados de dor, e o mesmo nível de dor pode ser sentido por diferentes pessoas como expressão de maior ou menor sofrimento. Algumas áreas da saúde buscam uma compreensão da relação dor e sofrimento, como na referência à dor oncológica como "dor total", nos indicando que o paciente de câncer, além de sofrer insuportáveis dores físicas, sofre o estigma social causado pela pressão psicológica de sofrer uma doença "incurável" - por mais que o tratamento nesta área já tenha melhorado.

De fato, o modo como sofremos está relacionado a muitos aspectos de nossa vida, desde a nossa experiência histórica, cultural e até religiosa. João Paulo II, em sua Encíclica Evangelium Vitae que comemorou 20 anos de sua publicação em 2015, dentre tantos temas relacionados à questão da vida, reflete criticamente sobre "uma atmosfera cultural que não vê qualquer significado nem valor no sofrimento, antes considera-o como mal por excelência, que se há de eliminar a todo o custo"'. Esta concepção reflete-se na busca por meios cada vez mais eficazes de sanar a dor.

Com efeito, quando prevalece a tendência para apreciar a vida só na medida em que proporciona prazer e bem-estar, o sofrimento aparece como um contratempo insuportável, de que é preciso libertar-se a todo o custo. A morte, considerada como absurda quando interrompe inesperadamente uma vida ainda aberta para um futuro rico de possíveis experiências interessantes, torna-se, pelo contrário, uma libertação reivindicada, quando a existência é tida como já privada de sentido porque mergulhada na dor e inexoravelmente votada a um sofrimento sempre mais intenso ${ }^{2}$.

O ser humano não é marcado por um determinismo biológico, ele difere neste aspecto por sua abertura ilimitada devido à sua incompletude. Esta abertura torna-o capaz de adaptar-se aos mais diversos ambientes e também de reagir a eles, caso estes venham causar dor e sofrimento, fabricando até tecnologias que lhe permitem enfrentar a morte, transformando a natureza e assim, fazendo história. "A história não é forjada pela força da razão, mas pela astúcia do desejo"3. E é o

\footnotetext{
JOÃO PAULO II. Evangelium Vitae (EV). São Paulo: Paulinas, 1995, n. 15.

Ibidem, n. 64.

MURARO, Rose Marie; BOFF, Leonardo. Feminino e masculino: uma nova consciência para o encontro das diferenças. Rio de Janeiro: Sextante, 2002, p. 130.
} 
desejo ilimitado de viver que leva o ser humano a desenvolver sua razão em prol de recursos que prolonguem sua existência.

Tendo presente estas considerações, abordaremos neste artigo a morte, o sofrimento e a dor, tratando estas questões no contexto da bioética, num diálogo com a teologia, a partir do ensinamento e da postura de João Paulo II sobre estes temas.

\section{Bioética}

Inúmeras situações, contextos e acontecimentos modernos apontam para a relevância da bioética nos nossos dias ${ }^{4}$. O nascimento da bioética é determinado por três fatores: o primeiro de caráter histórico pela experiência da II Guerra Mundial, a Declaração Universal dos Direitos Humanos e a criação da Organização das Nações Unidas (ONU); o segundo fator é de caráter científico pelo progresso da engenharia genética; e o terceiro de caráter jurídico que frente ao galopante progresso impõe-se a necessidade de adequadas regulamentações. Na Igreja, o seu reconhecimento se deu exatamente no contexto do pontificado de João Paulo II, que diante da complexidade das questões éticas relacionadas à vida, considerava a bioética um dos sinais positivos dos nossos tempos:

Particularmente significativo é o despertar da reflexão ética acerca da vida: a aparição e o desenvolvimento da bioética favoreceu a reflexão e o diálogo - entre crentes e não crentes, como também entre crentes de diversas religiões - sobre problemas éticos, mesmo fundamentais, que dizem respeito à vida do homem ${ }^{5}$.

Para a fé cristã, as questões da bioética têm como pano de fundo do discernimento ético o princípio fundamental da dignidade humana que se exprime no grande sim à vida desde sua concepção até sua morte natural ${ }^{6}$. Também a UNESCO aprovou e publicou várias declarações nesta área como a Declaração Universal sobre Bioética e Direitos Humanos de 2005, isto após refletir "sobre os rápidos avanços na ciência e na tecnologia, que progressivamente afetam nossa compreensão da

\footnotetext{
4 Para aprofundar o tema sugere-se a leitura do primeiro capítulo da obra de SANCHES, M.A. Bioética, ciência e transcendência. São Paulo: Loyola, 2004.

5 JOÃO PAULO II. Evangelium Vitae (EV). São Paulo: Paulinas, 1995, n. 27.

6 Congregação para a Doutrina da Fé. Instrumento Donum Vitae, 1988, n. 1.
} 
vida e a vida em si", resultando, deste modo, em forte exigência de uma resposta global perante as implicações éticas de tais desenvolvimentos ${ }^{7}$.

Cada vez mais tomamos consciência de que a Bioética tem origem diversa, mas merece destaque o movimento que ocorreu nos Estados Unidos e que deu status de disciplina a esta nova área de estudo e seu reconhecimento social. Já na década de 1970 o termo 'bioética' aparece na obra do oncologista Van Rensselaer Potter, em seu livro Bioethics: Bridge to the Future (1971). Nesta mesma década surgem os centros de Bioética como o Instituto Kennedy de Ética, da Universidade Georgetown, em Washington, DC, onde o obstetra e fisiologista André Hellegers se destaca em bioética e se torna o responsável pela divulgação e popularização do termo 'bioética' para significar uma nova área de pesquisa.

Há uma dificuldade na conceituação de bioética, por isso mesmo, percebemos a necessidade de abordar o assunto. Francisco de Assis Correia indica que "Bioética - de vida e ética - é um neologismo que significa ética da vida. Este primeiro sentido já indica um conteúdo de enorme abrangência: tudo o que é vida lhe compete" ${ }^{8}$. Assim, portanto, já reconhece a dificuldade de dar à bioética uma definição adequada.

A bioética entra em cena para a defesa da vida. Deste modo, a própria bioética se apresenta de maneira aberta e se articula com diferentes temas. Há certo consenso de que a bioética é uma parte da ética. Num primeiro momento a bioética se aproxima da ética médica, no entanto, logo se reconhece que esta disciplina milenar, não dá conta de toda a problemática que a bioética pretende abordar. Por isso hoje se afirma a importância da ética médica como uma parte da bioética.

Aliada a estas alterações na ética, há o fato de que nas últimas quatro décadas foi registrado um progresso espantoso no campo da 'biotecnociência' '. É a partir deste ponto de vista que Durant Guy vai afirmar que a bioética é uma parte da ética, mas a parte que é relativa aos problemas colocados pelo progresso das ciências biomédicas, problemas novos, ou nova consideração de antigos problemas. Em síntese, esta é

\footnotetext{
UNESCO. Declaração Universal sobre Bioética e Direitos Humanos, 2005.

8 CORREIA, Francisco de Assis. Alguns desafios atuais da bioética. In: PESSINI, Leo, BARCHIFONTAINE, Christian de Paul (Org.). Fundamentos da bioética. São Paulo: Paulus, 1996, p. 30.

9 SCHRAMM, Fermin Roland. Bioética e biossegurança. In: COSTA, S.I.F., OSELKA, G., GARRAFA, V. (Coord.). Iniciação à bioética. Brasília: Conselho Federal de Medicina, 1998, p. 218.
} 
a primeira definição geral: "a bioética é a pesquisa ética aplicada às questões colocadas pelo progresso biomédico"10.

Portanto, é necessário apontar que há uma imprecisão em identificar o 'bio' de bioética com 'vida', como foi visto acima, conceituando a bioética como ética da vida. A partícula 'bio' aqui quer designar, como bem esclarece o próprio Potter, "o conhecimento biológico"11. Portanto, não se refere à vida em geral, mas às 'ciências da vida', do modo como é entendido na divisão acadêmica das ciências. Ou seja, o 'bio' de bioética vem de biologia, biociências, biotecnologia, ou em resumo, de biotecnociência.

É nesta direção que aponta a definição da Enciclopédia de Bioética, na sua segunda edição, que entende esta disciplina "como sendo o estudo sistemático das dimensões morais - incluindo visão, decisão, conduta e normas morais - das ciências da vida e da saúde, utilizando uma variedade de metodologias éticas num contexto interdisciplinar" 12 .

Para se aproximar melhor do objeto da bioética entendemos que é necessário deixar o conceito de 'vida' aberto a toda a sua complexidade e delimitar melhor o tipo de 'intervenção técnica'. A bioética não trata de qualquer intervenção técnica, mas daquelas intervenções que as chamadas 'ciências da vida e da saúde' provocam sobre a vida. Por isso sugere-se aqui uma definição: "bioética é a ciência do comportamento moral dos seres humanos à frente de toda intervenção da biotecnociência e das ciências da saúde sobre a vida, em toda a sua complexidade"13.

Concluindo, entendemos que um conceito de bioética deverá contemplar estes três elementos: a avaliação (a ética), da ação (um determinado tipo de técnica), sobre a vida (compreendida em toda a sua complexidade). É a partir da inter-relação entre estes três elementos que o objeto específico desta nova ciência, que já caminhou algumas décadas, precisa ser criticamente aprofundado.

\section{Bioética e a negação/aceitação da morte}

Para muitas pessoas a morte e o processo de morrer ainda constituem um tabu, algo que não se fala no cotidiano, como um assunto a ser

\footnotetext{
${ }^{10}$ DURANT, Guy. A bioética: natureza, princípios, objetivos. São Paulo: Paulus, 1995, p. 22.

${ }^{11}$ PESSINI, Léo e BARCHIFONTAINE, Christian de Paul. Problemas atuais de bioética. 4. ed. São Paulo: Loyola, 1997, p. 14.

12 REICH, W. T. (Ed.). Encyclopedia of Bioethics. 2. ed., v. 1. 1995, p. XXI.

${ }^{13}$ SANCHES, M. A. Bioética, ciência e transcendência. São Paulo: Loyola, 2004, p. 21.
} 
evitado, que paradoxalmente revela um "eclipse do valor da vida"14. Negar ou ocultar a morte pode significar uma tentativa de negação de nossa própria condição de finitude e isto pode repercutir nos cuidados que devemos aos que sofrem e principalmente no cuidado às pessoas que se encontram na fase final da vida.

Este tema se torna relevante, pois a morte não é uma experiência secundária para os seres vivos, mas a sua própria limitação. Falar da morte é falar do momento em que os seres vivos se deparam com a sua barreira final, sua contradição, sua provisoriedade. Para nós, seres humanos, que temos pleno conhecimento e certeza da morte, ela se torna realmente a grande pergunta para a existência. Pergunta esta perante a qual a vida, aparentemente, se curva e não responde, ou responde se submetendo.

Os autores Pessini e Barchifontaine ${ }^{15}$ nos lembram que na sociedade, com o avanço das ciências biomédicas, passa-se não mais a falar da morte como um momento, mas como um processo. Isso porque o tempo decorrido da descoberta da doença à morte passouse de cinco dias para cinco anos e até mais. Neste âmbito a psiquiatra de origem suíça Elisabeth Kubler-Ross, no decorrer de suas pesquisas com profissionais de saúde e nos cuidados do doente em fase terminal, desenvolveu junto aos moribundos, inclusive em seu próprio processo pessoal, um trabalho que permitiu identificar um conjunto de reações emocionais pelas quais passam o doente em fase terminal. Este estudo de Elisabeth foi muito difundido.

Segundo ela, o morrer do ser humano normalmente se dá em cinco fases de duração bastante variada: primeiro estágio de "negação", pois ao tomar conhecimento da fase terminal de sua doença a maioria dos pacientes reage dizendo: "não, eu não, não pode ser verdade". Num segundo estágio, quando não é mais possível manter firme a negação, ele é substituído por sentimentos de "raiva, de revolta, de inveja e de ressentimento". No terceiro estágio surge a "barganha" quando o ser humano tenta negociar com Deus uma saída para a crise, este estágio é o menos conhecido, pois a maioria das barganhas são feitas com Deus, mantidas geralmente em segredo.

14 JOÃO PAULO II. Evangelium Vitae (EV). São Paulo: Paulinas, 1995, n. 10.

15 PESSINI, L.; BARCHIFONTAINE, C. P. Problemas atuais de bioética. 4. ed. São Paulo: Loyola, 1997, p. 295 ss. 
No quarto estágio surge a "depressão," quando o paciente não pode mais negar a doença e sua revolta e raiva cederão lugar a um sentimento de grande perda que poderá apresentar características que vão desde a perda de sua imagem à perda de suas funções. No quinto estágio da "aceitação" o paciente supera a revolta e a depressão e passa a lidar melhor com sua situação. É também o período em que a família geralmente carece de ajuda, compreensão e apoio, mais do que o próprio paciente.

Estas fases são vivenciadas de modo diferente pelos pacientes, pois há pacientes que lutam até o fim, que se debatem e se agarram à esperança, tornando impossível atingir o estágio de aceitação ${ }^{16}$. A pesquisa concluiu com um dado de que a esperança é a única coisa que geralmente persiste em todos os estágios. "É a esperança que de vez em quando se insinua, de que tudo isso passa de um pesadelo irreal de que acorde uma manhã e veja tudo resolvido"17.

Em bioética há, portanto, muitos estudos manifestando a preocupação pela qualidade dos últimos dias do moribundo e pela relevância da própria morte e do próprio morrer. Magali Boemer se refere ao paciente terminal como aquele que, "não tem oportunidade de escolha, e, portanto, raramente toma decisões. A comunidade do hospital decide por ele quanto ao seu tratamento, sua alta, sua cirurgia"18. O paciente terminal, enquanto humano, não escolhe a doença que o está levando para a morte, mas precisa poder escolher, fazer opções - na medida do possível - sobre o tratamento, e até decidir sobre os riscos que quer correr. Sem esses riscos não há ações significativas para o ser humano e, sem eles, não há liberdade.

Portanto, é necessário que ele seja encarado como ser reflexivo, que toma consciência de si mesmo, que além da liberdade de optar, tem de manter sua autonomia, no que se refere à capacidade de decidir o que é "bom", o que é seu "bem-estar", de acordo com seus valores, expectativas, necessidades, prioridades e crenças próprias. Autonomia e direitos que muitas vezes são negados aos pacientes em fase terminal. Segundo Fortes:

\footnotetext{
${ }^{16}$ KUBLER-ROSS, Elizabeth. Sobre a morte e o morrer. 2. ed. São Paulo: Martins Fontes, 1985, p. 49-100.

17 Ibidem, p. 146-149.

${ }^{18}$ BOEMER, Magali Roseira. A morte e o morrer. São Paulo: Cortez, 1986, p. 130.
} 
(...) por muito tempo a tradição hipocrática dos médicos não estimulou a autonomia do paciente, privilegiando a ação beneficente por parte dos profissionais, o "fazer o bem" ao paciente, o "cuidar" ainda que contrariamente à vontade do paciente ${ }^{19}$.

A bioética tem por objetivo humanizar o ambiente de clinicas e hospitais e, em particular, promover os direitos do paciente para exercer uma sadia liberdade e terminar seus dias com uma morte digna.

\section{Bioética e os Cuidados no fim da vida}

O morrer pode ser vivido de formas diversas, e isto certamente dependerá do conjunto de sentidos que for dado para esta experiência. Para Léo Pessini, é saudável sermos peregrinos. Contudo, não se trata de aceitar passivamente a morte como consequência do descaso pela vida, que é causada pela violência, acidentes e pobreza. Frente a este cenário, a indignação ética é necessária para se assumir um compromisso com a vida vulnerável.

Podemos ser curados de uma doença classificada como sendo mortal, mas não de nossa mortalidade e finitude humanas. Esta condição de existir não é uma patologia! Quando esquecemos isso, acabamos caindo na tecnolatria e na absolutização da vida biológica pura e simplesmente. Insensatamente procuramos a cura da morte, e não sabemos mais o que fazer com os pacientes fora de possibilidades terapêuticas ${ }^{20}$.

Podemos dizer que a reflexão em Bioética percorreu um logo caminho buscando distinguir o compromisso em cuidar dos mais vulneráveis sem cair na idolatria da técnica, pois esta, se aplicada sem avaliação, pode causar ainda mais dor e sofrimento a quem devia levar alívio e conforto. Neste caminho a bioética passa por muitas fases e uma

${ }^{19}$ FORTES, Paulo Antonio de Carvalho. Ética e Saúde - questões éticas-deontológicas e legais autonomia e direito paciente - Estudo de casos. EPU - Editora Pedagógica e Universitária, 2002, p. 38.

${ }^{20}$ PESSINI, Léo. Morrer com dignidade é decorrência do viver dignamente. Disponível em: $<$ http://www.Cuidadospaliativos.com.br>, ABCP, 10/03/2007, p. 2. 
delas é a distinção dos termos relacionados com o processo de morrer, principalmente: Eutanásia, Distanásia, Ortotanásia.

\section{Eutanásia}

O termo eutanásia - do grego eu: boa, tanatos: morte - ao longo da história podia significar a "boa morte", ou seja, a morte rápida a um soldado irremediavelmente ferido ou a morte a que eram condenadas as crianças com alguma má-formação, como na antiga Esparta. Com o avanço da medicina o termo passa a ser usado para significar o abreviar da vida de um doente em fase terminal. Na segunda metade do século XX o termo eutanásia passou a ser substituído por homicídio piedoso, indicando que o abreviar a vida do paciente estava motivado pelo busca ao alívio do sofrimento, pela 'piedade'. Também foi muito usada a expressão 'suicídio assistido' quando o paciente solicita apoio ou ajuda para dar fim à própria vida. Esta prática recebeu pouco apoio de organizações de saúde e a grande maioria dos países a considera um crime.

A Igreja Católica rejeitou esta prática na Declaração Sobre Eutanásia, pela Congregação para Doutrina da Fé e João Paulo II retomou este ensinamento na Encíclica Evangelium Vitae. Contudo, é necessário primeiro termos clareza do que estamos falando para um correto juízo moral da eutanásia. Nesse sentido, por eutanásia deve-se entender uma ação ou uma omissão que, por sua natureza e nas intenções, provoca a morte com o objetivo de eliminar o sofrimento. Assim, a eutanásia deve ser identificada ao nível das intenções e ao nível dos métodos empregados ${ }^{21}$.

O papa situa o problema da eutanásia num contexto de desvalorização da vida e de uma sociedade que mede as pessoas por meio da sua utilidade. A Evangelium Vitae vê na prática da eutanásia um dos sintomas da cultura da morte e do descarte marginalizando pessoas idosas, deficientes e/ou vulneráveis a partir de critérios utilitaristas de eficiência e produção ${ }^{22}$. Nesse contexto utilitarista do ser humano, surge o desejo de apoderar-se da morte, provocando-a antes do tempo e, deste modo, pondo fim "docemente" à vida própria ou alheia.

\footnotetext{
${ }_{21}$ JOÃO PAULO II. Encíclica Evangelium Vitae, 1995, n. 65.

${ }^{22}$ Ibidem, n. 15.
} 
Estamos aqui perante um dos sintomas mais alarmantes da cultura de morte que avança, sobretudo, nas sociedades do bem-estar, caracterizada por uma mentalidade eficientista que faz aparecer demasiadamente gravoso e insuportável o número crescente das pessoas idosas e debilitadas ${ }^{23}$.

Deste modo, aquilo que poderia parecer lógico e humano, quando visto em profundidade, é apresentado inversamente como algo absurdo e desumano. É importante identificar que na base de muitas solicitações de eutanásia, há ausência de solidariedade e presença de abandono e solidão, sendo que a necessidade real é de "melhor assistência, tratamento personalizado, sedativos eficazes, espiritualidade e ternura humana" 24 .

\section{Excesso terapêutico}

Paralelo à condenação da eutanásia, que abrevia criminosamente a vida humana, rejeita-se também, veementemente, a atitude que prolonga irresponsavelmente a agonia de um paciente terminal. Entendemos a questão, às vezes denominada de distanásia, excesso ou obstinação terapêutica, como sendo uma ação, intervenção ou procedimento médico que não atinge o objetivo de beneficiar a pessoa em fase terminal e que prolonga inútil e sofridamente o processo de morrer, procurando distanciar a morte ${ }^{25}$. A encíclica Evangeluim Vitae assim se pronunica:

Distinta da eutanásia é a decisão de renunciar ao chamado "excesso terapêutico", ou seja, a certas intervenções médicas já inadequadas à situação real do doente, porque não proporcionadas aos resultados que se poderiam esperar ou ainda porque demasiado gravosas para ele e para a sua família. Nestas situações, quando a morte se anuncia iminente e inevitável, pode-se em consciência renunciar a tratamentos que dariam somente um prolongamento precário e penoso da vida, sem, contudo, interromper os cuidados normais devidos ao doente em casos semelhantes ${ }^{26}$.

\footnotetext{
23 JOÃO PAULO II. Encíclica Evangelium Vitae, 1995, n. 64.

${ }_{24}$ PESSINI, L. Bioética: um grito por dignidade de viver. 3. ed., Paulinas, 2008, p. 176-177.

25 PESSINI,L. Questões éticas-chaveno debate hodierno sobre a distanásia. In:GARRAFA, V.; PESSINI, L. Bioética poder e injustiça. São Paulo: SBB/São Camilo/Loyola, 2003, p. 398.

${ }^{26}$ JOÃO PAULO II. Encíclica Evangelium Vitae, 1995, n. 65.
} 
As novas possibilidades terapêuticas exigem do profissional de saúde um novo discernimento. Há menos de cem anos a resposta a esta pergunta: "devemos utilizar sempre todos os meios disponíveis para prolongar a vida de um paciente?" era um simples "sim", pois os meios disponíveis eram escassos. Nos dias atuais a resposta a esta pergunta exige uma análise bem mais profunda da situação do paciente, das condições da família, dos valores envolvidos, das possibilidades terapêuticas, entre outros elementos complexos.

Também a respeito desta questão a Igreja tem se posicionado de tal modo que tem ajudado os profissionais de saúde a se posicionarem promovendo o cuidado dos pacientes sem cometer excessos terapêuticos. Aqui se trata da distinção entre meios ordinários e extraordinários, hoje também chamados de meios proporcionais ou desproporcionais. Deste modo, a resposta da Igreja à pergunta se "devemos utilizar sempre todos os meios disponíveis" é clara: todos os meios ordinários ou proporcionais devem ser utilizados, mas não há obrigação moral de usar sempre todos os meios extraordinários ou desproporcionais.

Perante a iminência de morte inevitável, apesar dos meios empregados, é lícito em sua consciência tomar a decisão de renunciar a certos tratamentos que buscam somente uma prorrogação precária e penosa da vida, mas não se podem interromper os tratamentos normais que se devem aos enfermos em tais $\operatorname{casos}^{27}$.

Assim, o paciente, o profissional da saúde ou os familiares podem limitar a utilização de meios que apenas prolonguem abusivamente o processo de morte e a agonia do paciente. Nesse caso é necessário distinguir situações muitos parecidas que podem levar à confusão, por isso vamos chamar a atenção para o 'verbo' utilizado que expressa uma determinada atitude. Primeiramente, é aceitável 'renunciar' - isto significa que o paciente está consciente e em condições de avaliar a situação do que é proporcional ou desproporcional para ele mesmo. Se o paciente renuncia conscientemente a um tratamento extraordinário, cabe aos profissionais de saúde e familiares acatar a decisão do paciente.

27 Declaração da Congregação da Doutrina da Fé Iura et bona, 05 de maio, 1980. In: DEZINGER, Heinrich. Compêndio dos símbolos, definições e declarações de fé e moral. 2. ed. rev. e amp., São Paulo: Paulinas, Loyola. 2013, p. 1102. (Atualizada por Johan Konings, com base na $43^{\mathrm{a}}$ edição alemã, 2010). 
É também aceitável 'limitar' - isto se dá num quadro onde o paciente já não pode manifestar sua vontade e os profissionais, juntamente com a família resolvem 'limitar esforços terapêuticos'. Evidentemente que nestes casos trata-se de evitar os esforços terapêuticos extraordinários ou desproporcionais, após uma adequada avaliação das condições do paciente.

No entanto, a decisão de 'suspender' procedimentos terapêuticos tem provocado muito debate na área da bioética. Isto porque significa que um procedimento já fora iniciado e que o ato de suspender tal procedimento passa a ter uma relação direta com o abreviar a morte do paciente. Nestas situações suspender um procedimento pode equivaler à prática da eutanásia. No Brasil esta situação tem gerado debates e predomina entre os profissionais de saúde a postura de 'não suspender, nem interromper' procedimentos já iniciados.

Atualmente, o alto desenvolvimento técnico gera ambientes cada vez mais desumanos, nos quais a dignidade humana acaba ficando em segundo plano. Segundo Schramm $^{28}$ houve uma desapropriação da morte na era moderna, no qual a pessoa afasta-se do processo de morrer, perdendo sua autonomia nesse momento de existência. É comum o drama da morte gerar um certo afastamento das pessoas em geral, inclusive daqueles que estão próximos à pessoa. As mortes nas UTIs são sempre processos complexos, com grande risco de se promover uma distanásia. Muitos processos distanásicos são realizados em pessoas à beira da morte a fim de evitar o que erroneamente se entende como eutanásia, ou seja, o apressamento da morte ${ }^{29}$.

É importante percebermos que a situação de excesso terapêutico se torna muito frequente por causa da dificuldade em avaliar a situação de fim da vida em tempo real e muitos profissionais de saúde, por causa desta dificuldade, iniciam alguns suportes vitais e continuam a mantê-los por longo tempo, pois após iniciado, há muita dificuldade em interrompê-los. Esta é uma realidade com que as pessoas enfermas se deparam em nossa sociedade, realidade de sofrimento, sem perspectivas, nas terapias intensivas. No dizer de Kubler-Ross esta situação tende a um agravamento cada vez maior:

${ }^{28}$ SCHRAMM, Fermin Roland. Bioética e biossegurança. In: COSTA, S. I. F.; OSELKA, G.; GARRAFA, V. (Coord.). Iniciação à bioética. Brasília: Conselho Federal de Medicina, 1998, p. 218.

${ }^{29}$ KOVÁCS, Maria Júlia. Morrer com dignidade. In: SIQUEIRA, José Eduardo; ZOBOLI, Elma; KIPPER, Délio José (Org.). Bioética clínica. São Paulo: Gaia, 2008, p. 165. 
Se dermos uma olhada no futuro, ele nos mostrará uma sociedade na qual mais e mais pessoas são "mantidas vivas" tanto com máquinas que substituem órgãos vitais como computadores verificando periodicamente para ver se alguma função fisiológica tem que ser substituída por equipamento eletrônico. Poder-se-á estabelecer centros cada vez mais em número, onde todos os dados técnicos são coletados e onde o acender de uma luz indicará quando um paciente expira, a fim de desligar o equipamento automaticamente, para poupá-lo ou utilizá-lo em outro paciente ${ }^{30}$.

Como consequência dessa dificuldade, vemos surgir em nossa sociedade os hospitais-empresa, com seus técnicos mais qualificados, com equipamentos mais sofisticados capazes de prolongar a agonia de uma pessoa durante meses, anos, mas incapazes de devolver-lhes a vida, a vida verdadeira, a vida com sentido.

\section{Morrer com dignidade}

Nos últimos anos os estudiosos da bioética têm apresentado um novo termo, a 'ortotanásia' enfatizando a necessidade de se promover um ambiente que permita a morte com dignidade. Onde pode haver renúncias ou limitações aos cuidados terapêuticos extraordinários, evitando os excessos que apenas prolongam a agonia, mas no qual todos os cuidados ordinários e paliativos são mantidos. A linguagem, nesta área, deve ser precisa para se evitar a confusão entre eutanásia, que é eticamente inaceitável, e a ortotanásia que é defendida como moralmente recomendada. O Código de Ética Médica atual, no Brasil, indica que nas situações clínicas irreversíveis e terminais, o médico evitará a realização de procedimentos diagnósticos e terapêuticos desnecessários, propiciando aos pacientes sob sua atenção todos os cuidados paliativos $\operatorname{apropriados}^{31}$.

Este código condena a eutanásia, no artigo 41, dizendo que é vedado ao médico "abreviar a vida do paciente, ainda que, a pedido deste ou de seu representante legal", deixando claro que isto não pode justificar o excesso terapêutico, ao afirmar:

\footnotetext{
${ }^{30}$ KUBLER-ROSS, Elizabeth, op. cit. p. 21-22.

${ }^{31}$ CFM. Resolução no 1931/2009. Princípios Fundamentais, XXII. Disponível em: <http:// www.portalmedico.org.br/resolucoes/CFM/2009/1931_2009.htm>.Acesso em:19jul. 2010.
} 
Nos casos de doença incurável e terminal, deve o médico oferecer todos os cuidados paliativos disponíveis sem empreender ações diagnósticas ou terapêuticas inúteis ou obstinadas, levando sempre em consideração a vontade expressa do paciente ou, na sua impossibilidade, a de seu representante legal ${ }^{32}$.

No processo de terminalidade, deve-se levar em conta não a quantidade de vida que resta à pessoa, mas sim a qualidade de vida que deve permanecer até o final, que no conceito de Pessini, inclui muito mais que simplesmente morrer sem dor, sem sofrimento, mas morrer reconciliado consigo mesmo, com as pessoas ao seu redor, com seu mundo e para quem possui fé, com seu Deus ${ }^{33}$. Desta forma, é importante assegurar aos pacientes fora de possibilidades de cura, atenção integral, que contemple os aspectos físicos, emocionais, sociais e espirituais.

Dentro dos limites, é também importante que o cuidador espiritual trabalhe junto ao paciente pela promoção de sua autonomia, mesmo que relativa, e sua dignidade. Se o próprio cuidador não tiver uma concepção que supere o "não há nada mais a ser feito", certamente não conseguirá dar o apoio espiritual e de comunicação ao doente e à família. O ambiente, cercado por uma atmosfera de respeito, conforto, suporte, comunicação e espiritualidade, certamente influirá no bem estar e até no controle dos sintomas do paciente. O cuidado será marcado, portanto, pela compaixão, pelo amor, no ato e na arte do cuidar, tão essenciais ao processo com pacientes fora de possibilidades terapêuticas de cura.

É interessante perceber, que até mesmo a qualidade da morte pode ser diferente, quando em ambiente tranquilizador, como pode ser o ambiente familiar. Principalmente para os idosos a hospitalização é marcada por uma separação de ambientes familiares, tornando-se um local estranho que desrespeita hábitos tão arraigados ${ }^{34}$. Devidamente acompanhados por cuidadores espirituais e de saúde física, tanto doentes, quanto familiares, podem passar por um desfecho um pouco mais tranquilo da doença terminal.

\footnotetext{
${ }^{32}$ Idem.

33 PESSINI, Léo; BERTACHINI, Luciana (Org.). Humanização e cuidados paliativos. 2. ed.. São Paulo: Loyola, 2004.

${ }^{34}$ KOVÁCS, Maria Júlia. Morrer com dignidade. In: SIQUEIRA, José Eduardo; ZOBOLI, Elma; KIPPER, Délio José (Org.). Bioética clínica. São Paulo: Gaia, 2008, p. 167.
} 


\section{A postura de João Paulo II diante da morte}

João Paulo II em uma de suas catequeses que compõe o conjunto de textos intitulados "Teologia do Corpo" (1979-1984) define a morte como antítese da vida, uma experiência totalmente nova frente à experiência de vida que o ser humano primeiramente faz. Esta experiência contrária de não existência torna-se alternativa entre a morte e a imortalidade que entra na definição do ser humano e que pertence "desde o princípio" ao significado da sua solidão diante do próprio Deus ${ }^{35}$.

Seu ensinamento foi contundente contra a eutanásia, mas ao mesmo tempo deixou claro o seu questionamento contra os excessos terapêuticos, num equilíbrio que valoriza os cuidados de saúde e ao mesmo tempo aponta que a vida humana não deve se submeter a uma ditadura da tecnologia. Há, sem dúvida, a obrigação moral de se tratar e procurar curar-se, mas aceitar a morte é um sinal de maturidade humana, psíquica e espiritual. Deste modo ele nos ensina que "a renúncia a meios extraordinários ou desproporcionados não equivale ao suicídio ou à eutanásia; exprime, antes, a aceitação da condição humana defronte à morte" 36 .

Se os ensinamentos de João Paulo II foram lúcidos e inequívocos mais forte ainda, porque coerente, foi sua maneira de lidar com a própria enfermidade e sua morte. É do conhecimento de todos que ele viveu seus últimos anos num processo de enfermidade cada vez mais debilitante. $\mathrm{Na}$ perspectiva da fé cristã, "a esperança na ressurreição prometida projeta uma luz nova sobre o mistério do sofrimento e da morte e infundem no crente uma força extraordinária para se abandonar ao desígnio de Deus" 37 .

Papa Francisco, na época arcebispo de Buenos Aires, fez uma declaração em 2005 para o processo de beatificação e canonização de João Paulo II publicada no dia 27 de julho de 2014 pelo jornal italiano Avvenire. No que diz respeito à vida do Servo de Deus, o cardeal de Buenos Aires Jorge Mario Bergoglio disse que no último período de sua vida é sabido por todos, inclusive pelos meios de comunicação e de

\footnotetext{
35 João Paulo II desenvolveu no início de seu pontificado entre 1979 e 1984 um conjunto de Catequeses correlacionadas que, após estudos, foi intitulada como Teologia do Corpo. A Catequese mencionada aqui reflete que na própria definição do ser humano está a alternativa entre morte e imortalidade, proferida em 31/10/1979.

36 JOÃO PAULO II. Encíclica Evangelium Vitae, 1995, n. 65.

${ }^{37}$ Ibidem, n. 67.
} 
informação, "como ele soube aceitar as próprias doenças e sublimá-las colocando-as no seu plano de realizar a vontade de Deus". Da mesma forma salienta que "João Paulo II nos ensinou, não escondendo nada aos outros, a sofrer e a morrer, e isso, em minha opinião, é heroico".

De fato, não recusou recursos a vários tratamentos, pois inúmeras vezes se submeteu à cirurgias e outras intervenções médicas, mas no final João Paulo II renunciou ele mesmo aos excessos terapêuticos, desproporcionais a sua real condição de saúde, pedindo para morrer em sua residência. Vejamos o relato de seus últimos momentos por Renato Buzzonetti:

Na manhã de sábado, 2 de abril, pelas 7:30h foi celebrada a missa na presença do santo padre que já começava a revelar indícios, embora descontínuos, de comprometimento de seu estado de consciência.

Pelo fim da manhã, registrou-se uma brusca subida de temperatura. Pelas 15:30h, com voz fraquíssima e palavra estropiada, em língua polaca, o Santo Padre pedia: 'Deixem-me partir para o Senhor'.

Os médicos davam-se conta de que o fim estava iminente e que qualquer novo procedimento terapêutico agressivo teria sido inútil. Pelas 21:37h o Papa exalava seu último suspiro ${ }^{38}$.

Deste modo, João Paulo II coroava com a própria vida o seu ensinamento propiciando a todos nós um vivo testemunho de equilíbrio entre saber cuidar da própria saúde e ter maturidade para viver bem seus últimos momentos. Toma ele mesmo a decisão de não ser submetido a cuidados desproporcionados que, sem dúvida, apenas prolongaria sua agonia. Assim, ele que vive unido a Cristo em vida, une-se a Ele também no sofrimento e vivencia a própria morte com a nobreza e dignidade de quem se nutre da esperança pascal.

\section{Considerações finais}

A condição humana inclui a morte como ato final da vida, quaisquer que sejam as condições sociais, psíquicas, culturais ou econômicas em que tenha se desenvolvido, independentemente do sucesso que o indivíduo tenha alcançado ou das frustrações que tenha vivido. A morte

${ }^{38}$ BUZZONETTI. Renato. Deixem-me partir: o poder da fraqueza de João Paulo II. São Paulo: Paulus, 2006, p. 71-72. 
iguala a todos, independentemente de religião, status social, idade, ideologias, nacionalidade, etc. Ela revela a fragilidade da vida e o quanto somos solitários no morrer: ninguém foge à morte e ninguém pode morrer por outro.

A Igreja, portadora da esperança cristã, deixa bem clara a sua mensagem: é contra a eutanásia, pois a vida não pode ser deliberadamente interrompida; desaconselha a distanásia, pois o excesso de terapias desproporcionais pode levar a um prolongamento angustiante do processo de morte; aceita e recomenda a ortotanásia, pois entende que aceitar a morte é sinal de maturidade humana, moral, psíquica e espiritual.

A Igreja na América Latina vive sob o impacto do Documento de Aparecida, fruto da 5a Conferência do CELAM, ocorrida em 2007 e eu gostaria de concluir este texto sob sua inspiração. Este documento é muito rico e a passagem seguinte reflete um pouco de sua profundidade:

A missão do anúncio da Boa Nova de Jesus Cristo tem destinação universal. Seu mandato de caridade alcança todas as dimensões da existência, todas as pessoas, todos os ambientes da convivência e todos os povos. Nada do humano pode lhe parecer estranho ${ }^{39}$.

Este trecho apresenta a cada cristão, a necessidade de se envolver com a realidade humana em toda a sua plenitude, em todos os seus aspectos, consciente de que viver a aventura de responder ao amor de Deus é viver intensamente cada instante da vida humana, com toda a sua concretude, com toda sua materialidade. Este texto é otimista, pois acredita no ser humano e entende que toda busca da verdade, incluindo a verdade científica, vem de Deus e por isso pode ser iluminada por Ele.

A inspiração de Aparecida, expressa no texto acima, reforça no cristão a forte indicação de que há toda uma gama de situações que precisam ser vivenciadas à luz do mistério de Cristo, pois para Ele, "nada do humano pode lhe parecer estranho": o cuidado do doente, a paciência com o idoso, o levar ao serviço de saúde, a espera, muitas vezes longa; a difícil tarefa de decidir se aceita ou não o tratamento... Enfim, uma infinidade de situações bem humanas, vivenciadas numa rede de relações de parentesco e de amigos que precisam ser iluminadas pela mensagem do Evangelho, pois é neste ambiente que cada um de

${ }^{39}$ CELAM, Documento de Aparecida, n. 380. 
nós é chamado a viver a nossa vida em Cristo. A bioética pode nos levar a esta reflexão, incentivando o estudo, promovendo o debate para crescermos como cristãos adultos, conscientes e livres.

\section{Referências}

BERGOGLIO, Jorge Mario. Declaração para a causa de beatificação e canonização de João Paulo II. Roma, 2005. Disponível em: <http://www.maeperegrina.org.br/ wojtyla-nos-ensinou-a-sofrer-e-a-morrer/>. Acesso em: 28 jul. 2014.

BOEMER, Magali Roseira. A morte e o morrer. São Paulo: Cortez, 1986.

BUZZONETTI. Renato. Deixem-me partir: o poder da fraqueza de João Paulo II. São Paulo: Paulus, 2006.

CELAM: Conselho Episcopal Latino-Americano. Documento de Aparecida. Texto conclusivo da V Conferência Geral do Episcopado Latino-Americano e do Caribe. Brasília: CNBB, 2007.

CFM. Resolução no 1931/2009 - art. 41, parágrafo único. Disponível em: <http://www. portalmedico.org.br/ resolucoes/CFM/2009/1931_2009.htm>. Acesso em: 19 jul. 2015.

CONGREGAÇÃO PARA A DOUTRINA DA FÉ. Instrumento Donum Vitae: sobre algumas questões de bioética. 1988. Disponível em: <http://www.vatican.va/roman curia/congregations/cfaith/documents/rc_con_cfaith_doc_20081208_dignitaspersonae_po.html>. Acesso em: 05 jul. 2016.

. Instrumento Iura et bona. 05 de maio, 1980. In: DEZINGER, Heinrich. Compêndio dos símbolos, definições e declarações de fé e moral. 2. ed. rev. e amp. São Paulo: Paulinas, Loyola, 2013. p. 1101-1102. (Atualizada por Johan Konings, com base na 43a edição alemã, 2010).

CORREIA, Francisco de Assis. Alguns desafios atuais da bioética. In: PESSINI, Leo; BARCHIFONTAINE, Christian de Paul (Org.). Fundamentos da bioética. São Paulo: Paulus, 1996.

DURANT, Guy. A bioética: natureza, princípios, objetivos. São Paulo: Paulus, 1995.

FORTES, Paulo Antonio de Carvalho. Ética e saúde - questões éticas-deontológicas e legais autonomia e direito paciente - Estudo de casos. E.P.U - Editora pedagógica e Universitária, 2002. p. 38.

JOÃO PAULO II. Evangelium Vitae (EV). São Paulo: Paulinas, 1995. n. 27.

. Na própria definição do homem está a alternativa entre morte e imortalidade. Roma, 1979. Disponível em: $<$ http://teologiadocorpo.com.br/007-na-propria-definicaodo-homem-esta-a-alternativa-entre-morte-e-imortalidade-31101979/>.

KOVÁCS, Maria Júlia. Morrer com dignidade. In: SIQUEIRA, José Eduardo; ZOBOLI, Elma; KIPPER, Délio José (Org.). Bioética clínica. São Paulo: Gaia, 2008. p. 164-168. 
KUBLER-ROSS, Elizabeth. Sobre a morte e o morrer. 2. ed. São Paulo: Martins Fontes, 1985.

PESSINI, Léo. Morrer com dignidade é decorrência do viver dignamente. Disponível em: <http://www.Cuidadospaliativos.com.br>. ABCP, 10/03/2007, p. 2.

. Questões éticas-chave no debate hodierno sobre a distanásia. In: GARRAFA, V.; PESSINI, L. Bioética poder e injustiça. São Paulo: SBB/São Camilo/Loyola, 2003. p. 398.

PESSINI, Léo; BARCHIFONTAINE, Christian de Paul de. Problemas atuais de bioética. 4. ed. São Paulo: Loyola, 1997.

(Org.). Fundamentos da bioética. São Paulo: Paulus, 1996.

PESSINI, Léo; BERTACHINI, Luciana (Org.). Humanização e cuidados paliativos. 2. ed. São Paulo: Loyola, 2004.

REICH, W. T. (Ed.). Encyclopedia of bioethics. 2. ed. 1995. v. 1. p. XXI.

SANCHES, Mário Antônio. Bioética, ciência e transcendência. São Paulo: Loyola, 2004.

SCHRAMM, Fermin Roland. Bioética e biossegurança. In: COSTA, S. I. F.; OSELKA, G., GARRAFA, V. (Coord.). Iniciação à bioética. Brasília: Conselho Federal de Medicina, 1998.

UNESCO. Declaração Universal sobre Bioética e Direitos Humanos, 2005. Disponível em: <http://bioeticaediplomacia.org/wp-content/uploads/2013/10/declaracao_univ_ bioetica_dir_hum.pdf $>$. Acesso em: 06 mar. 2014.

ZOBOLI, E.; SARTÓRIO, N. A. Em enfermagem. In: SIQUEIRA, J. E.; ZOBOLI, E.; KIPPER, D. J. (Org.). Bioética clínica. São Paulo: Gaia, 2008. p. 157. 